\title{
Synthesis and investigation of dispersed metal oxide-graphene photoelectrode material
}

\author{
S.V. Shulga, N.V.Sigareva, N.M. Moshkivska \\ Chuiko Institute of Surface Chemistry of the National Academy of Sciences of Ukraine, Kyiv 03164, Ukraine, \\ E-mail: sergey.v.shulga@ukr.net
}

Abstract - The technology of forming solar cells by layer-drawing of its components using the method of painting or spraying at room temperature is perspective to significantly reduce the cost of finished products. The goal of present work is to describe preparation and characterization of $\mathrm{TiO}_{2}, \mathrm{ZrO}_{2}-\mathrm{few}$ layered graphene (FLG) composite materials for the fotovoltaic working electrode.

Keywords - photoanode material, graphene nanoparticles, composite electrode.

The uniform distribution of the conductive carbon phase between the semiconductor grains was provided by co-esterification of the ethanol dispersion of graphene particles and gel-like hydrated metal oxide from aqueous solutions upon a $\mathrm{pH}$ increase. The research was carried out by methods of electrochemical impedance and scanning electron microscopy[1]. To find the conductivity at the boundary between the grains $\left(\sigma_{g r}\right)$, the Nyquist diagram is constructed in the coordinates Z "(Z) (Fig 1).
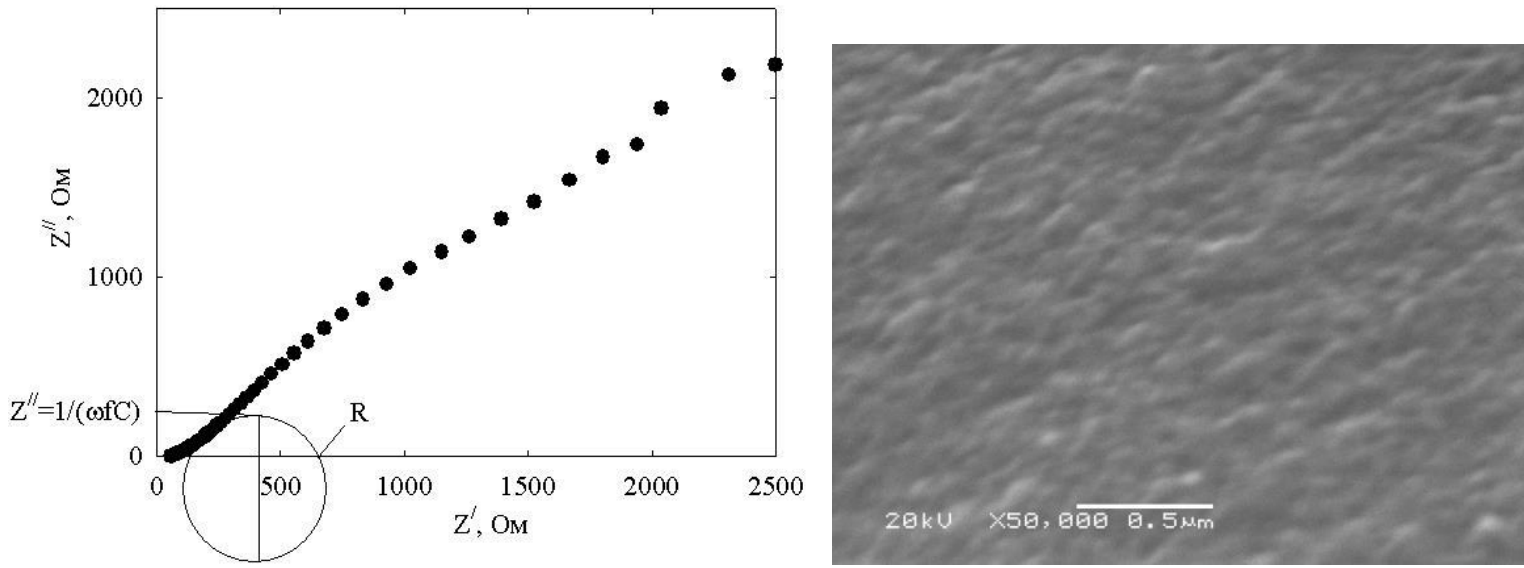

Fig 1. Nyquist diagram and SEM image of the FLG - semiconductor composite.

The circle position corresponds to the maximum on the admittance curve $\mathrm{Y}(f)$, where $f$ is the frequency. The value $\sigma_{g r}$ is estimated as $0.025 \mathrm{Ohm}^{-1} \mathrm{~m}^{-1}$. This value is ten times less than that of direct current $\sigma_{d c}$, which is typical for disperse samples.

The capacity of grain boundaries is $6.24 \times 10^{-5} \mathrm{~F}$. The high measured value $\sigma_{d c}$ shows that the amount of graphene in the composite exceeds the percolation threshold. This indicates that graphene particles are in contact for the composite. The latter provides a continuous conductivity and promotes the charge transfer in the conposite.

\section{Conclusion}

The analysis of impedance spectra showed the presence of composite structures that are able to transfer and accumulate energy. The synthesized composites can be used as photoconductive materials for flexible solar cells.

\section{References}

[1] Mattew P. Genowese, “ Sun-Believable Solar Paint. A Transformative One-Step Approach for Designing Nanocrystalline Solar Cells ” ACS Nano, vol 6 ,(1), pp 865-872, 2012. 